\title{
State and Dynamics of Child Disability in Modern Russia
}

\author{
Brusneva V.V. ${ }^{1,{ }^{*}}$ Gorbunova V.V. ${ }^{1}$ Mayatskaya N.K. ${ }^{2}$ Grazhdankina L.Yu. ${ }^{1}$ \\ Bondarenko K.D. ${ }^{1}$
}

\author{
${ }^{1}$ Department of Economics and Social Work, Stavropol State Medical University, Stavropol, Russia \\ ${ }^{2}$ Department of Defectology and Russian Language, Stavropol State Medical University, Stavropol, Russia \\ *Corresponding author. Email: Brusneva_valeria@mail.ru
}

\begin{abstract}
The paper presents the analysis of the state and dynamics of child disability in Russia taking into account structure, gender and level of certain classes of diseases on the basis of official statistics. It defines features in the development of child disability in modern Russia alongside with the main factors causing child disability and possible ways of its prevention. Modern Russia is facing an increase in the absolute number of children and adolescents recognized as disabled for the first time. The main population of disabled children form three classes of diseases: mental disorders and behavioral disorders, nervous system diseases, congenital abnormalities, development defects, deformities and chromosomal abnormalities. The regional uneven spread of child disability is typical for the area. It was concluded that the problem of child disability requires not only medical but also social, economic, political and psychological resources of the society.
\end{abstract}

\section{Keywords: child disability, structure, general and primary disability, prevention}

\section{INTRODUCTION}

In modern society, the issue of improving the standard and quality of life of persons with disabilities is a strategic goal and objective of the state social policy, as defined by the basic principles of the United Nations, according to which persons with disabilities are equal in civil, political, social and cultural rights with all others. Children with disabilities form a special priority of the state.

The child disability in modern society is one of the most complex and multidimensional problems that attracts the attention of both the public and public authorities. Child disability is, on the one hand, a leading indicator of the state of health of the child population of the country, and, on the other hand, a criterion for assessing the efficiency of health and social service institutions.

Child disability has several aspects of influence on the social state: medical, social, moral and economic. In modern Russia, the current problem is the growth of child disability, which not only negatively affects the state of human capital of the Russian society, but also leads to an increase in budgetary expenditures on social support and medical care for this category of citizens.

The analysis of the state and dynamics of child disability is the basis for the state policy of social protection and support, directions for prevention and rehabilitation.

The purpose of the study is to analyze the state, dynamics and peculiarities of child disability in the Russian Federation and to identify promising areas of its prevention.

\section{METHODS AND MATERIALS}

The study was based on official statistics characterizing the state of child disability in modern Russia since 20162018, information from the federal state information system Federal Register of Disabled Persons.

\section{RESULTS}

According to the Pension Fund of the Russian Federation, the total number of disabled children in Russia is steadily growing. Thus, if in 2009 (as of January 1, 2009) it was 515.0 thousand people, in 2015 it made 617.0 thousand children, in 2018 - 651.0 thousand children, and by January 1, $2019-670.1$ thousand children [1].

At the same time, taking into account general demographic trends, the proportion of children with disabilities in the child population has almost been constant in recent years and amounts to about $2.2 \%$. At the same time, the level of the total accumulated population of disabled children per 10 thousand children in the Russian Federation has been gradually increasing throughout 2016-2019: 212.7-215.1-221.0-223.5 accordingly.

At the same time, child disability is not evenly distributed among the regions of the Russian Federation. By the beginning of 2019, the highest level of the total accumulated population of disabled children per 10 thousand children in the region was found in the Chechen 
Republic (1225.0), the Republic of Ingushetia (932.7), the Republic of Dagestan (521.2), the Karachai-Cherkess Republic (337.0) and the Kursk Region (267.4).

The lowest indicators of child disability are observed in the following regions: Khanty-Mansi Autonomous District - Yurga (153.3), Yaroslav Region (154.3), Primorsky Krai (154.4), Saratov Region (159.5), Perm Krai (162.6).

At the beginning of 2019, in terms of gender the total accumulated number of disabled children in the Russian Federation was dominated by boys and amounted to $57.0 \%$. The proportion of girls made $43.0 \%$.

As of 01.01.2019, the distribution of disabled children by age in the structure of the total accumulated population showed that $45.0 \%$ were children at the age of 8-14, $30.0 \%$ - children at the age of 4-7, $15.0 \%$ - children under 3 years, $10.0 \%$ - children at the age of 15-18.

As of 01.01.2019, the structure of the total accumulated population of disabled children in the Russian Federation by classes of diseases leading to disability was the following:

- mental and behavioral disorders $(24.3 \%)$;

- $\quad$ nervous system diseases $(23.2 \%)$;

- congenital abnormalities (malformations), deformities and chromosomal abnormalities $(17.7 \%)$;

- $\quad$ endocrine disorders $(7.8 \%)$

- $\quad$ ear diseases $(4.7 \%)$;

- diseases of an eye and its appendages (4.6\%);

- $\quad$ musculoskeletal disorders $(3.7 \%)$;

- $\quad$ respiratory diseases $(3.7 \%)$.

Other diseases accounted for not more than $10.3 \%$

As of 01.01 .2019 , the absolute number of disabled children with mental disorders made 175,187 persons. Among them 59.4\% are mentally retarded disabled children, the share of disabled children with psychological development disorders made $21.9 \%$ (including autism $11.1 \%)$, the share of disabled children with organic (including symptomatic) mental disorders was equal to $14.8 \%$, the share of disabled children with schizophrenia, schizotypal and crazy delusional disorder equaled $3.5 \%$.

The absolute number of disabled children with nervous system diseases was less than 165,430. Among them, the largest proportion were disabled children with cerebral palsy and other paralytic syndromes (55.4).

The absolute number of disabled children with congenital anomalies amounted to 117,288. The proportion of disabled children with congenital abnormalities of the circulatory system was higher and made $24.8 \%$, the proportion of disabled children with congenital abnormalities and deformities of the musculoskeletal system amounted to $19.8 \%$, with chromosomal disorders $-14.2 \%$, with abnormalities of nervous system development - $10.7 \%$, with cheilognatho-palatoschisis - $7.6 \%$, with urinary system abnormalities - $5.5 \%$, with digestive abnormalities $5.1 \%$; with abnormalities of eye, ear, face and neck $4.6 \%$, with congenital abnormalities of respiratory organs $-2.9 \%$, with abnormalities of genital organs $-0.1 \%$, with other congenital abnormalities $-4.7 \%$.

Studying of structure of the accumulated population of disabled children in the Russian Federation for 01.01.2019 by weight of physical dysfunctions showed that among all disabled children the disabled people having restrictions of activity of $1^{\text {st }}$ degree of intensity prevailed and made $46.3 \%$, disabled children having restrictions of activity of $2^{\text {nd }}$ degree made $36.2 \%, 3^{\text {rd }}$ degree $-13.1 \%$.

The primary disability is characterized by the number of persons with impaired health who have applied for the first time to medical and social institutions for expertise and have been recognized as disabled. According to federal statistical reports, in 2016 about 89,739 persons under 18 applied to medical and social expertise institutions for the first time. In 2017 their number decreased slightly - to 88,752 people $(-1.1 \%)$, in 2018 - to 88,002 people $(-0.8 \%)$. In general, there was an increase in the number of primary applications by children and adolescents (their legal representatives) to medical and social expertise institutions and in the number of children and adolescents recognized as disabled for the first time.

The primary child disability rate per 10 thousand children has fluctuated since 2012-2018 within the following ranges: 26.9-24.7 respectively. Despite the increase in the absolute number of children and adolescents recognized as disabled for the first time, the level of child disability per 10,000 of the corresponding population has decreased between 2012 and 2018 and by 2018 it made 24.7 per 10,000 children.

In the structure of disability by age the majority were children at the age of $0-3$, which made $41.9-40.3-$ $38.2 \%$ in 2016-2018. There is a tendency towards the reduction of specific weight of disabled children aged from 0 up to 3 , which is most likely caused by prenatal diagnostics of a number of diseases and efficiency of health care to children at early age.

The proportion of disabled children aged 4-7 in 20162018 increased to $27.1-27.8-28.5 \%$, respectively. The proportion of persons with disabilities aged 8-14 years was significantly lower and ranged from 24.8-25.2-26.1\% respectively. The proportion of persons with disabilities aged 15-17 was the lowest, but there was an upward trend from $6.3 \%$ in 2016 to $6.7 \%$ in 2017 and $7.2 \%$ in 2018

The most acute problem at present is the disability of the child population due to mental and behavioral disorders (with mental retardation prevailing); nervous system disorders (with infantile cerebral palsy prevailing); congenital abnormalities (developmental defects prevailing), deformations and chromosome breakage (circulatory system abnormalities prevailing). These classes of diseases, which by 2018 in the structure of primary childhood disability constituted in total about $62 \%$ of cases, mainly form child disability [2]. 
Thus, the following features can be distinguished in the development of child disability in modern Russia:

- despite the growing absolute number of children and adolescents for the first time recognized as disabled people, the level of child disability for the last period decreases by 10 thousand of the corresponding population;

- level of disability is generally widespread among boys;

- in the structure of the general disability in the accumulated population of disabled children nearly a half $(45 \%)$ are children at the age of $8-14$, only $10.0 \%$ - children at the age of $15-17$;

- $\quad$ with age increase the specific weight of disabled children in the general structure of primary child disability on average decreases, the highest level of primary child disability is noted at the age of 0 3 years;

- the main population of disabled children is formed by three classes of diseases: mental and behavioral disorders with mental subnormality prevailing; nervous system disorders with the prevalence of infantile cerebral palsy; congenital abnormalities (developmental defects), deformities and chromosome breakage with circulatory system defects prevailing;

- $\quad$ every year there is a growing number of disabled children with mental disorders with mental subnormality prevailing;

- the specific weight of disabled children with nervous system disorders in the structure of primary disability of child population changes slightly with cerebral palsy playing the prevailing role;

- in the structure of child disability, the number of disabled children with congenital anomalies (development defects), deformities and chromosome breakage decreases, which can be explained by the increase in the efficiency of prenatal diagnosis of malformations, availability and hi-tech medical care in the post-natal period or at early stages of child development;

- the percentage of children with heavy physical dysfunctions ( 3 degrees) in the accumulated population of disabled children makes $13.1 \%$. The most pronounced physical dysfunction in children are caused by the nervous system disorders;
- child disability is unevenly distributed among the regions of the Russian Federation.

The individual needs of children with disabilities in rehabilitation and abilitation activities are determined by the individual rehabilitation or abilitation program of a disabled child issued by federal state institutions of medical and social expertise. The vast majority of disabled children requires medical rehabilitation, recovery treatment, medicine provision - $95.9 \%$. Besides, $24.4 \%$ of children with disabilities need to be rehabilitated through technical means. There is a need for social and environmental rehabilitation, abilitation for $82.3 \%$, sociopsychological rehabilitation, abilitation - $70.9 \%$, sociocultural rehabilitation, abilitation $-55.5 \%$, social and domestic adaptation - $54.7 \%$ of disabled children. Moreover, $58.5 \%$ of children with disabilities need special education, including conditions for the organization of education. The need for adaptive physical culture and sports is defined for $18 \%$ of children with disabilities [3].

So far, insufficient attention has been paid to the problem of the disability of surviving premature children, which is relevant to all countries. Domestic and foreign literature reflect the consensus of researchers on the fact that the achievements of perinatology led not only to an increase in infant survival, but also to an increase in disability disorders in surviving children. The incidence of disability among children brought to life increases with the decrease of their body weight. Among newborns with a body weight of $1000 \mathrm{~g}$ and lower, severe disability disorders occur in $28 \%$ of cases, and less severe disorders occur in $44 \%[4,5]$.

With the transition to the new birth record criteria recommended by WHO, as well as the improvement of the care of premature and low-weight newborns, the number of newborns is increasing. In the Russian Federation, the proportion of premature children born with low, very low and extremely low body weight among children born alive currently makes $11.8 \%$, i.e. more than 200 thousand people [4].

The adverse consequences of disorders are a heavy burden for families and the healthcare system. A recent report states that in the United States the average cost of medical care for a child born between 28 and 31 weeks is US\$95 in the first year alone [6]. The consequences of premature delivery can be felt throughout the future life of a surviving child, leading to disorders in the development and functioning of the nervous system due to the increased risk of cerebral palsy, causing learning disorders, as well as affecting physical health, increasing the risk of noncommunicable diseases.

The analysis of the causes of childhood disability shows that in its structure mental and behavioral disorders, nervous system diseases and congenital abnormalities steadily occupy more than $60 \%$ of diseases that lead to disability of children of all age groups. Hereditary diseases and cerebral palsy contribute significantly to the formation of child disability in this group of causes [7, 8]. It is these diseases that lead to severe physical dysfunctions and 
irreversible losses of labor and intellectual potential of the country.

One of the main areas in preventing the child disability should be the reduction of the so-called general genetic burden, which occurs in more than $5 \%$ of the population [8]. Prenatal and preimplantation genetic diagnosis plays an important role in reducing the genetic burden in the population thus deceasing the risk of child delivery with a hereditary disease. In this regard, it is necessary to raise the awareness of doctors and the population of the country, especially women, about the real possibilities of prenatal and preimplantation genetic diagnosis.

The detection of biochemical markers of brain cell damage and repair in case of cerebral circulation disorders as a result of perinatal lesions, genetically caused lesions and brain injuries in children, development of recommendations for therapy and reduction of disability cases based on the results of these studies, including prevention of infantile cerebral palsy, seem quite promising $[9,10]$.

The negative factor leading to the growth of childhood disability is lifestyle, unsustainable nutrition, spread of bad habits, lack of physical activity, which leads to excessive body weight of children and adolescents, especially in the obesity phase, development of diseases of the circulatory system, which determine the occurrence of early vascular diseases (heart attacks and strokes).

Among the environmental factors in the Russian Federation, the natural iodine deficiency, which covers about $50 \%$ of the territories of the country, is of great importance. The cessation of iodine prevention leads to goitrous endemia, which adversely affects the health of children, leads to the delay of mental, physical and sexual development [2].

Child disability has family, economic and social effects associated with negative impacts on the family, health system, intergenerational, psychosocial, emotional and economic problems, high cost of treatment and rehabilitation, risk of disability in descendants [11].

Another equally acute problem of modern Russian society is the existence of barriers between persons with disabilities and the society caused by the fact that the society tries to create the most favorable hothouse conditions for the development of persons with disabilities thus fostering their consumer attitude to healthy people and society. At the same time, the successful integration of children with disabilities into society and the inclusion of children with disabilities in labor and social activities are possible only with the active participation of children with disabilities and their families in rehabilitation programs. However, according to experts, for various reasons, more than $50 \%$ of children with disabilities and their legal representatives refuse to participate in the rehabilitation activities declared in the individual rehabilitation program [3].

The solution to this problem will determine the need to establish effective mechanisms for motivation and participation of children with disabilities and their families in rehabilitation activities and programs that ensure their integration into the society, including active labor and social activities.

\section{CONCLUSION}

Child disability today is one of the most complex social problems that no society can solve. On the one hand, modern medical technologies allow preserving pregnancy, "give life", support children with various health disorders, and on the other - in most cases they lead to disability.

The increase in the number of disabled children leads to an increase in the state's budget expenditure for treatment and medical rehabilitation of disabled children, socio-economic support for families raising disabled children and children with disabilities, creation of a modern integrated infrastructure for rehabilitation and educational assistance to disabled children and children with disabilities, introduction of inclusive education technologies, special jobs, etc.

Currently, child disability is no longer a purely medical phenomenon. It requires social, economic, political and psychological resources of the society, especially the family. A disabled child in the family fundamentally changes self-determination, social status and strategies of family behaviour, dramatically reduces material level, opportunities for leisure and rest, resource of social and psychological support of other family members.

The prevention of child disability, including health and social interventions, is essential for preserving the intellectual, labour and reproductive potential of the country.

\section{REFERENCES}

[1] Population, Position of disabled people, Federal Public Statistics Service. Retrieved from: http://www.gks.ru/wps/wcm/connect/rosstat_ main/rosstat/ru/statistics/population/ disabilities/ (date of access: 30.09.2019).

[2] A.A. Baranov, L.S. Namazova-Baranova, R.N. Terletskaya, E.V. Antonova, Problems of child disability in modern Russia, J. of the Russ. Acad. of Med. Sci. 72(4) (2017) 305-312.

[3] V.V. Savchenko, N.K. Mayatskaya, M.G. Gevandova, Problems of providing medical, social and rehabilitation assistance to disabled children, Med. Bull. of the North Caucasus 11(1) (2016) 117-118.

[4] L.S. Namazova-Baranova, I.A. Deev, O.S. Kobyakova et al., Features of somatic pathology in children with low, very low and extremely low body weight at birth at different age periods of life, Bull. of Siber. Med. 15(4) (2016) 140-149.

[5] K. Patra, D. Wilson-Costello, H.G. Taylor et al., Grades I-II intraventricular hemorrhage in extremely low birth weight infants: effects on neurodevelopment, J. Pediatr. 149(2) (2006) 169-173.

[6] M. Angsupaisal, C.G. Maathuis, M. Hadders-Algra, Adaptive seating systems in children with severe cerebral palsy across International Classification of 
Functioning, Disability and Health for Children and Youth version domains: a systematic review, Dev. Med. Child. Neurol. 57(10) (2015) 919-930.

[7] E.S. Tkachenko, O.P. Goleva, Cerebral palsy - one of the leading causes of childhood disability of modern times, Eurasian Union of Sci. 7-3 (2015) 86-89.

[8] B. Adair, A. Ullenhag, P. Rosenbaum et al., Measures used to quantify participation in childhood disability and their alignment with the family of participation-related constructs: a systematic review, Dev. Med. Child. Neurol. 60(11) (2018) 1101-1116.

[9] L.P. Andreeva, N.P. Kuleshov, G.R. Mutovin et al., Hereditary and congenital diseases: contribution to childhood morbidity and disability, approaches to prevention, Pediatr. J. named after G.N. Speransky 86(3) (2007) 8-14.

[10] G.A. Karashadze, A.V. Anikin, E.P. Zymina et al., Current data on pathogenesis and treatment of hypoxic-ischemic brain lesions in newborns, Pediatr. Pharmacol. 13(5) (2016) 452-467.

[11] E.V. Smirnova, S.V. Mitrofanova, N.I. Medvedeva et al., Socio-economic mechanisms of supporting the institute of family in the conditions of financial crisis, Lecture Notes in Networks and Syst. 57 (2019) 795-802. 